\title{
Influence of FTO rs9939609 polymorphism on appetite, ghrelin, leptin, IL6,TNF $\alpha$ levels, and food intake of women with morbid obesity
}

This article was published in the following Dove Press journal: Diabetes, Metabolic Syndrome and Obesity:Targets and Therapy

\author{
Fernanda Cristina Carvalho \\ Mattos Magno' \\ Helena Chrispim Guaraná' \\ Ana Carolina Proença \\ Fonseca ${ }^{2}$ \\ Giselda Maria Kalil Cabello² \\ João Régis Ivar Carneiro 3 \\ Aline Pereira Pedrosa' \\ Ana Carolina Ximenes' \\ Eliane Lopes Rosado' \\ 'Institute of Nutrition, Federal \\ University of Rio de Janeiro, Rio de \\ Janeiro, RJ, Brazil; ${ }^{2}$ Oswaldo Cruz \\ Foundation (FIOCRUZ), Oswaldo \\ Cruz Institute (IOC), Human Genetics \\ Laboratory, Rio de Janeiro, RJ, Brazil; \\ ${ }^{3}$ Federal University of Rio de Janeiro, \\ University Hospital Clementino Fraga \\ Filho, Service of Nutrology, Rio de \\ Janeiro, RJ, Brazil
}

Background: The fat mass and obesity-related (FTO) gene has a strong relationship with obesity, extreme obesity and inflammatory state, and may also be associated with food intake regulation. Objective: The aim of the present study was to evaluate the influence of the rs 9939609 singlenucleotide polymorphism of the FTO gene on appetite, ghrelin, leptin, interleukin 6 (IL6), tumor necrosis factor $\alpha(\mathrm{TNF} \alpha)$ levels and food intake of morbidly obese women.

Materials and methods: The study comprised 70 women, aged between 20 and 48 years, from Rio de Janeiro, Brazil. The participants were selected according to the body mass index between 40 and $60 \mathrm{~kg} / \mathrm{m}^{2}$. Anthropometric and biochemical data were measured during fasting. Hormones and inflammatory data were measured before and after the participants ate an isocaloric meal. Dietary records were calculated and analyzed using a nutritional assessment program. Visual analog scales were used for behaviors of the sensations of appetite and food preferences. The FTO rs9939609 variant was genotyped using real-time polymerase chain reaction.

Results: Participants with the AA genotype had lower values of ghrelin and IL6 and higher values of leptin than those with TT and TA in the postprandial period. Comparing the plasma concentrations of ghrelin, insulin, IL6 and TNF $\alpha$ intragenotypes, it was observed that those with TT had decreased leptin and increased IL6 at the postprandial period. Subjects with TA showed increased postprandial IL6, and those with AA had decreased postprandial ghrelin. There was no difference in TNF $\alpha$ intra- and intergenotypes. The postprandial sensations of hunger were lower in AA than those with TT. There were differences between genotypes regarding ingested grams of protein by weight, cholesterol, B3, B5, B6 and B12 vitamins, and selenium potassium and sodium minerals.

Conclusion: These findings suggest that genetics may exert an influence on physiologic factors and might alter eating behavior.

Keywords: obesity, rs9939609, hormones, inflammatory cytokines, food intake, binge eating

\section{Introduction}

Today, the prevalence of obesity continues to increase and is one of the most challenging public health problems. Recent data show that the percentage of obese people has doubled in more than 70 countries between 1980 and $2015 .{ }^{1}$ Currently, more than 1.9 billion individuals are overweight, of which more than 600 million are obese. ${ }^{2}$ Furthermore, the medical costs associated with obese individuals is $\sim 30 \%$ greater than that of normal-weight people. ${ }^{3}$

In Brazil, 232 million adults had a body mass index (BMI) indicative of obesity in 2015. ${ }^{4}$ Between 2013 and 2014, our country was ranked fifth in the world in terms of obesity. ${ }^{5,6}$ Recently, the Risk and Protective Factors Surveillance Survey for Chronic
Correspondence: Fernanda Cristina Carvalho Mattos Magno Federal University of Rio de Janeiro, Institute of Nutrition Carlos Chagas Filho Avenue, 373 - CCS - block J - 2nd floor University City, Fundão Island, 21941-590 Rio de Janeiro, RJ, Brazil

Tel +552139386601

Fax +552122808343

Email fernandamattos.nut@gmail.com 
Diseases Telephone Survey indicated an increase in obesity in Brazil by $60 \%$ in the past 10 years, from $11.8 \%$ in 2006 to $18.9 \%$ in 2016 , that is, almost one in five Brazilians are obese. ${ }^{7}$ The prevalence for morbid obesity in the population is low (0.81\%), but led to costs totaling \$64.2 million in 2011, which amounts to almost a quarter of the costs attributable to obesity in the public health system. ${ }^{8}$

Body weight gain in the population is due to changes in dietary patterns and lifestyle, with increased energy intake and decreased physical activity. These changes appear to be the major factors leading to the increase of the global obesity epidemic in recent decades. However, there are clear differences in susceptibility between individuals or communities. ${ }^{9,10}$

The contribution of genetics to the development of obesity has been extensively investigated in genome-wide association studies, where the most common forms of obesity are polygenic, with the discovery of at least 77 loci associated with this disease $^{11}$ and 32 loci with a strong association in the increase of BMI. ${ }^{12}$ First described in 2007, it was demonstrated by bioinformatics tools that the fat mass and obesity-related (FTO) gene encodes a protein of the superfamily Fe (II) 2-oxoglutarate-dependent dioxygenases, with high similarity to the sequence of the DNA repair enzyme of Escherichia coli AlkB and its eukaryotic homologs AlkB 2 and 3 (ABH2 and 3 ). This gene also encodes a RNA adenosine demethylase, where the main substrate is N6-methyladenosine (m6A). ${ }^{13}$ The enzyme m6A RNA demethylase influences nucleic acid demethylation, which is important for epigenetic regulation (modifications of chromatin and DNA that activate or inhibit certain genes). ${ }^{14,15}$ The FTO gene is located on the long arm of chromosome 16 on position 12.2 and consists of nine exons, occupying an area of $>400 \mathrm{~kb} .^{14}$

The FTO gene was recently described and is strongly associated with obesity, ${ }^{14}$ extreme obesity ${ }^{11}$ and inflammatory state, ${ }^{16}$ and may also be associated with food intake regulation. ${ }^{17}$ FTO polymorphism has been studied in recent years and has been indicated as a predictor of obesity in several populations, ${ }^{18-20}$ where about $50 \%$ of the world population are the carriers of the "risk" allele. ${ }^{21}$ These studies indicated the association of FTO gene variants with food intake, raising the hypothesis of influence on hunger and satiety regulation ${ }^{17,22}$ probably related to the postprandial plasma concentrations of leptin and ghrelin hormones. ${ }^{23}$

The most studied FTO single-nucleotide polymorphism (SNP) is rs9939609, which comprises the A and T alleles, where the risk allele A seems to be directly related to increased accumulation of body fat, especially when pre- sented as an AA homozygote. ${ }^{18}$ In a pilot study published recently in Nigeria, rs9939609 was studied in a group of 103 obese and 98 controls, with mean age of 20 years. The results suggested that factors such as physical inactivity, high energy intake and sitting time had a mediating effect on the FTO gene variant for BMI, and that these variables may be playing an important role in the development and worsening of obesity. ${ }^{24}$

Therefore, the aim of the present study was to evaluate the influence of rs9939609 on appetite, ghrelin, leptin, interleukin 6 (IL6), tumor necrosis factor $\alpha$ (TNF $\alpha$ ) and food intake of morbidly obese women in Rio de Janeiro, Brazil.

\section{Materials and methods Study group: subjects}

The study comprised 70 women, aged between 20 and 48 years, from Rio de Janeiro, Brazil. The participants were selected according to BMI (between 40 and $60 \mathrm{~kg} / \mathrm{m}^{2}$ ) and the presence of obesity for at least 5 years. We excluded patients with renal failure, those with congestive heart failure, those diagnosed with dysgeusia, those who were in treatment for cancer, pregnant, those with a diagnosis of hypothyroidism or hyperthyroidism, those under the use of corticosteroids and medicines to lose weight or that influence the sensations of hunger and satiety (sibrutramin, orlistat, fluoxetine, topiramate and liraglutide), those in menopause, those who underwent surgery in the gastrointestinal tract, those who did not complete all of the steps described above, or who presented some intercurrence previously listed during the study. All participants provided written informed consent to participate in this study, and the protocol was performed according to the Declaration of Helsinki (1964). This study was approved by the Ethics and Research Committee of the University Hospital Clementino Fraga Filho, under the protocol CAAE no. 845.537 and registered in the Clinical Trials under the number NCT02598037.

\section{Clinical measurements}

The anthropometric data collected were body weight in kilograms, height, BMI, waist circumference (WC) and hip circumference (HC). The WC was measured at the midpoint between the lower margin of the last palpable rib and the top of the iliac crest. HC was measured around the widest portion of the buttocks. ${ }^{25}$ Waist-to-hip ratios were calculated by dividing $\mathrm{WC}$ by the HC. ${ }^{25}$

Serum samples were collected after 12 hours of an overnight fasting. Triglycerides (TGs), total cholesterol, high-density lipoproteins (HDLs), low-density lipoproteins 
(LDLs), very low-density lipoproteins (VLDLs), glucose and insulin fasting were measured. Ghrelin, leptin, IL6 and TNF $\alpha$ plasma were collected in tubes containing ethylenediaminetetraacetic acid and Pefabloc ${ }^{\circledR}$ (specific protein inhibitor), before and after the participants ate an isocaloric meal. The composition of the meals was elaborated with the same proportions of macronutrients (56\% carbohydrates, $18 \%$ proteins and $26 \%$ lipids) and the same volume $(350 \mathrm{~mL})$ for each volunteer.

\section{Dietary intake and physical activity}

Three nonconsecutive 3-day dietary records were filled in, reporting two typical days (weekdays) and one atypical day (weekend or holiday). ${ }^{26}$ Dietary records were calculated and analyzed using the nutritional assessment program AVANU$\mathrm{TRI}^{\circledR}$ version 4.0.

The International Physical Activity Questionnaire - short version was completed, adapted to the Portuguese language of Brazil. ${ }^{27}$ For the classification of the habitual practice of physical activity, the scores were considered: 1) sedentary, 2 ) insufficiently active, 3 ) active and 4) very active.

\section{Assessment of binge eating and behaviors of sensations of appetite and food preferences}

The binge eating scale was completed, adapted to the Portuguese language of Brazil. ${ }^{28}$ For the classification of the periodic binge eating, the following scores were considered: $\leq 17$ for without binge eating, 18-26 moderate binge eating and $\geq 27$ severe binge eating.

Visual analog scales (VASs) were used for behaviors of the sensations of appetite and food preferences. ${ }^{29}$ These sensations were assessed using a $10 \mathrm{~cm}$ VAS and were applied at intervals of 30 minutes during the study.

\section{DNA extraction and genotyping}

DNA was extracted from whole blood using a commercial DNA extraction kit (Invitrogen ${ }^{\mathrm{TM}}$ PureLink $^{\mathrm{TM}}$ Genomic DNA). The FTO variant rs9939609 was genotyped using real-time polymerase chain reaction with a TaqMan ${ }^{\circledR}$ assay (Thermo Fisher Scientific, Waltham, MA, USA). Amplification was performed in the Step One Plus ${ }^{\mathrm{TM}}$ and the genotypes were identified by SDS 2.3 software. Negative controls (all components excluding DNA) were included in all plates.

\section{Statistical analysis}

The Kolmogorov-Smirnov test was used to verify the distribution of variables. Data with non-Gaussian distribution were presented as median and quartile interval. The Kruskal-Wallis tests were used to analyze the data between groups, Wilcoxon-Mann-Whitney for analyses of paired and unpaired data and chi-square to evaluate the association between variables. Friedman test was used to compare the distributions of the quantitative variables and to verify that there was a significant variation in TT, TA and AA over the postoperative period (30-180 minutes), for hunger, satiety, gastric fullness, desire to eat savory and appetizer in those who presented differences between genotypes. All results were analyzed with the statistical analysis program SPSS version 21.0, considering significant values of $P<0.05$.

\section{Results}

In this present study, we analyzed the FTO rs9939609 polymorphism in our sample. The calculation of the HardyWeinberg equilibrium was performed, and it showed that genotypes were in equilibrium $\left(\chi^{2}=0.045 ; P=0.832\right) .{ }^{30,31}$ Our sample was stratified into groups according to genotype distribution, in which the frequencies were TT (33\%), TA $(50 \%)$ and AA (17\%). Moreover, the allele frequencies were $\mathrm{T}(58 \%)$ and $\mathrm{A}(42 \%)$. Low physical activity was observed in $57 \%$ of women with TT genotype, $69 \%$ with TA genotype and $75 \%$ with AA genotype.

Our results showed that women carrying the AA genotype have a higher level of preprandial insulin. There were no differences in other variables among genotypes (Table 1).

The effects of rs9939609 on hormone levels were analyzed in fasting and postprandial states. Table 2 shows that there was a difference between genotypes for ghrelin, leptin and IL6, in which the AA had lower values of ghrelin and IL6 and higher values of leptin than TT and TA in the postprandial period.

Comparing the plasma concentrations of ghrelin, insulin, IL6 and TNF $\alpha$ intragenotypes, it was observed that TT had decreased leptin and increased IL6 during the postprandial period. TA showed increased postprandial IL6 and AA decreased postprandial ghrelin. There was no difference in TNF $\alpha$ intra- and intergenotypes.

Considering the results found for the hormones previously referred to, it is important to complement with data related to the sensations of hunger and satiety, as well as food intake behavior.

Our results showed that hunger was higher at 60, 120 and 150 minutes in TT than in TA. Hunger in AA was lower than TT at 120 and 180 minutes. Satiety was higher at 30, 60 and 90 minutes in TA than in TT and AA. At 180 minutes, AA shows higher satiety than TT. Gastric fullness was lower at 90 minutes 
Table I Anthropometric and biochemical characteristics of the population

\begin{tabular}{|c|c|c|c|c|c|}
\hline Variables & Total (70) & TT (23) & TA (35) & AA (12) & $P$-value \\
\hline Age (years) & $36.0(30.0 ; 41.0)$ & $34.0(28.0 ; 38.0)$ & $35.0(30.0 ; 42.0)$ & $37.0(36.0 ; 40.0)$ & 0.056 \\
\hline \multicolumn{6}{|l|}{ Anthropometrics } \\
\hline Weight (kg) & $122.2(1 \mid 2.9 ; 135.6)$ & $121.5(\mid 13.6 ; 130.2)$ & $123.5(110.9 ; 135.0)$ & $130.9(108.7 ; 143.30)$ & 0.760 \\
\hline BMI $\left(\mathrm{kg} / \mathrm{m}^{2}\right)$ & $46.5(42.4 ; 50.8)$ & $46.6(42.4 ; 49.0)$ & $47.2(42.4 ; 52.6)$ & $47.8(43.8 ; 52.3)$ & 0.508 \\
\hline Waist $(\mathrm{cm})$ & $121.3(1 \mid 0.9 ; 132.1)$ & II8.0 (I 10.5; 131.0) & $122.0(1 \mid 2.0 ; 132.0)$ & $122.7(106.2 ; 136.2)$ & 0.644 \\
\hline Hip (cm) & 140.0 (I33.0; I47.3) & $140.0(135.0 ; \mid 45.5)$ & I $36.4(|32.5 ;| 48.0)$ & I 42.7 (I36.|; I50.0) & 0.269 \\
\hline WHR & $0.87(0.81 ; 0.92)$ & $0.85(0.81 ; 0.92)$ & $0.89(0.83 ; 0.92)$ & $0.87(0.78 ; 0.91)$ & 0.483 \\
\hline \multicolumn{6}{|l|}{ Biochemical } \\
\hline $\mathrm{TC}(\mathrm{mg} / \mathrm{dL})$ & $17 \mid .5$ (I50.5; I98.0) & I70.0 (I48.0; I87.0) & $178.0(|5| .0 ; 217.0)$ & $183.6(|5| .7 ; 203.2)$ & 0.311 \\
\hline LDL (mg/dL) & $105.5(95.0 ; 126.5)$ & $103.0(88.0 ; 119.0)$ & II 4.3 (95.0; 132.0) & II 5.7 (90.0; | 35.2) & 0.215 \\
\hline $\mathrm{HDL}(\mathrm{mg} / \mathrm{dL})$ & $44.0(39.0 ; 49.2)$ & $43.0(38.0 ; 51.0)$ & $44.9(36.0 ; 49.0)$ & $41.5(39.0 ; 49.5)$ & 0.559 \\
\hline $\operatorname{VLDL}(\mathrm{mg} / \mathrm{dL})$ & $22.2(15.0 ; 26.0)$ & $22.0(15.0 ; 25.0)$ & $22.6(14.0 ; 28.0)$ & $23.9(15.2 ; 24.7)$ & 0.887 \\
\hline TG (mg/dL) & $109.5(75.0 ; 129.3)$ & II $0.0(77.0 ; 127.0)$ & $109.4(69.0 ; 140.0)$ & $98.7(76.2 ; 123.5)$ & 0.965 \\
\hline Glucose (mg/dL) & 104.3 (9I.5; 108.0) & $96.0(90.0 ; 108.0)$ & 97.(92.0; 108.0) & $101.5(89.5 ; 116.5)$ & 0.859 \\
\hline Insulin $(\mathrm{mcU} / \mathrm{mL})$ & $20.9(14.8 ; 27.9)$ & $19.9(13.1 ; 23.4)$ & $21.8(16.7 ; 30.6)$ & $25.2(19.5 ; 34.6)^{\mathrm{a}}$ & 0.033 \\
\hline HOMA IR & $5.1(3.6 ; 7.5)$ & $4.6(2.9 ; 6.6)$ & $5.0(3.7 ; 8.2)$ & $6.2(4.1 ; 8.8)$ & 0.221 \\
\hline
\end{tabular}

Notes: HOMA IR index. Data of the population were expressed as median (interquartile). Kruskal-Wallis test used for comparison between genotypes, considering $P$-value $<0.05$. Wilcoxon-Mann-Whitney test for unpaired data considering $P$-value $<0.05$ for ${ }^{a}$ TT versus AA.

Abbreviations: BMI, body mass index; HDL, high-density lipoprotein; HOMA IR, Homeostatic Model Assessment of Insulin Resistance; LDL, low-density lipoprotein; TC, total cholesterol; TG, triglyceridess; VLDL, very low-density lipoproteins; WHR, waist-to-hip ratio.

Table 2 Hormone and cytokine data of the population

\begin{tabular}{|c|c|c|c|c|c|}
\hline Variables & Total (70) & TT (23) & TA (35) & AA (12) & $P$-value \\
\hline Fasting, ghrelin (pg/mL) & $42.9(27.4 ; 68.3)$ & $41.6(22.2 ; 77.6)$ & $41.9(33.7 ; 57.6)$ & $35.2(15.4 ; 47.9)$ & 0.172 \\
\hline Postprandial, ghrelin P $(\mathrm{pg} / \mathrm{mL})$ & $35.8(23.6 ; 52.4)$ & $49.3(26.8 ; 58.8)$ & $39.8(21.9 ; 53.7)$ & $29.4^{\mathrm{a}, \mathrm{b}}(16.9 ; 52.6)$ & 0.034 \\
\hline$P$-value & 0.003 & 0.153 & 0.564 & 0.010 & \\
\hline Fasting, leptin (pg/mL) & $35,898(26,567 ; 47,512)$ & $40,542(27,147 ; 53,68 I)$ & $33,653(25,468 ; 45,697)$ & $40,090(29,125 ; 47,021)$ & 0.340 \\
\hline Postprandial, leptin (pg/mL) & $35,952(26,210 ; 44,568)$ & $32,2979^{a}(21,850 ; 54,222)$ & $34,199(25,719 ; 40,925)$ & $46,555(37,303 ; 55,283)$ & 0.041 \\
\hline$P$-value & 0.172 & 0.002 & 0.413 & 0.051 & \\
\hline Fasting, IL6 (pg/mL) & $4.2(2.8 ; 6.3)$ & $4.7(2.7 ; 6.2)$ & $4.5(2.7 ; 7.1)$ & $3.8(3.2 ; 4.4)$ & 0.128 \\
\hline Postprandial, IL6 (pg/mL) & $5.1(3.0 ; 7.1)$ & $5.6^{\mathrm{a}}(3.0 ; 6.9)$ & $5.3(2.6 ; 8.3)$ & $3.5(3.0 ; 4.9)$ & 0.040 \\
\hline$P$-value & 0.002 & 0.006 & 0.016 & 0.875 & \\
\hline Fasting, TNF $\alpha(\mathrm{pg} / \mathrm{mL})$ & $3.1(2.0 ; 4.5)$ & $3.5(2.7 ; 5.3)$ & $2.9(1.8 ; 3.8)$ & $2.9(1.3 ; 2.9)$ & 0.164 \\
\hline Postprandial, TNF $\alpha$ (pg/mL) & $3.4(1.9 ; 4.9)$ & $3.5(1.9 ; 4.2)$ & $3.1(2.0 ; 5.0)$ & $3.2(1.9 ; 6.3)$ & 0.723 \\
\hline$P$-value & 0.399 & 0.057 & 0.732 & 0.564 & \\
\hline
\end{tabular}

Notes: Data of the population were expressed in median (interquartile). Kruskal-Wallis test used for comparison between genotypes and Wilcoxon test for paired data, considering $P$-value $<0.05$. Wilcoxon-Mann-Whitney test for unpaired data considering $P$-value $<0.05$ for ${ }^{\mathrm{a}} \mathrm{TT}$ versus AA and ${ }^{\mathrm{b} T T}$ versus AA.

Abbreviations: IL6, interleukin-6; TNF $\alpha$, tumor necrosis factor-alpha.

in TT than in TA. Desire to eat was lower in TA at 120 minutes than in TT and at 180 minutes than in TT and AA (Figure 1).

Desire to eat savory was lower at preprandial and postprandial 30, 120 and 150 minutes in TT than in TA and AA. In the postprandial period, desire to eat appetizer was lower at 60 minutes in TT than in TA and lower at 90, 120, 150 and 180 minutes than in TA and AA. There is no difference between genotypes for desire to eat sweet and fatty (Figure 2).

Additionally, it was observed that women carrying TT and TA genotypes were considered without binge eating and AA genotype with moderate binge eating according to the binge eating scores 14, 16 and 20, respectively.

Finally, 3-day dietary records were taken in order to analyze whether rs9939609 influences food intake of morbidly obese subjects. There were differences between genotypes regarding ingested grams of protein per kilogram of body weight (PTNg/kg BW); cholesterol; B3, B5, B6 and B12 vitamins and selenium potassium and sodium minerals. TT genotype consumed less $\mathrm{PTNg} / \mathrm{kg} \mathrm{BW}, \mathrm{B} 3$ and B12 vitamins and potassium than TA and AA genotypes. Subjects carrying the AA genotype consumed larger quantities of cholesterol, B5 and B6 vitamins and selenium and sodium than those with TT and TA genotypes. There is no difference in the food intake of the other parameters (Table 3 ).

\section{Discussion}

The purpose of this study was to investigate the hunger and satiety sensations, the release of hormones involved in this 

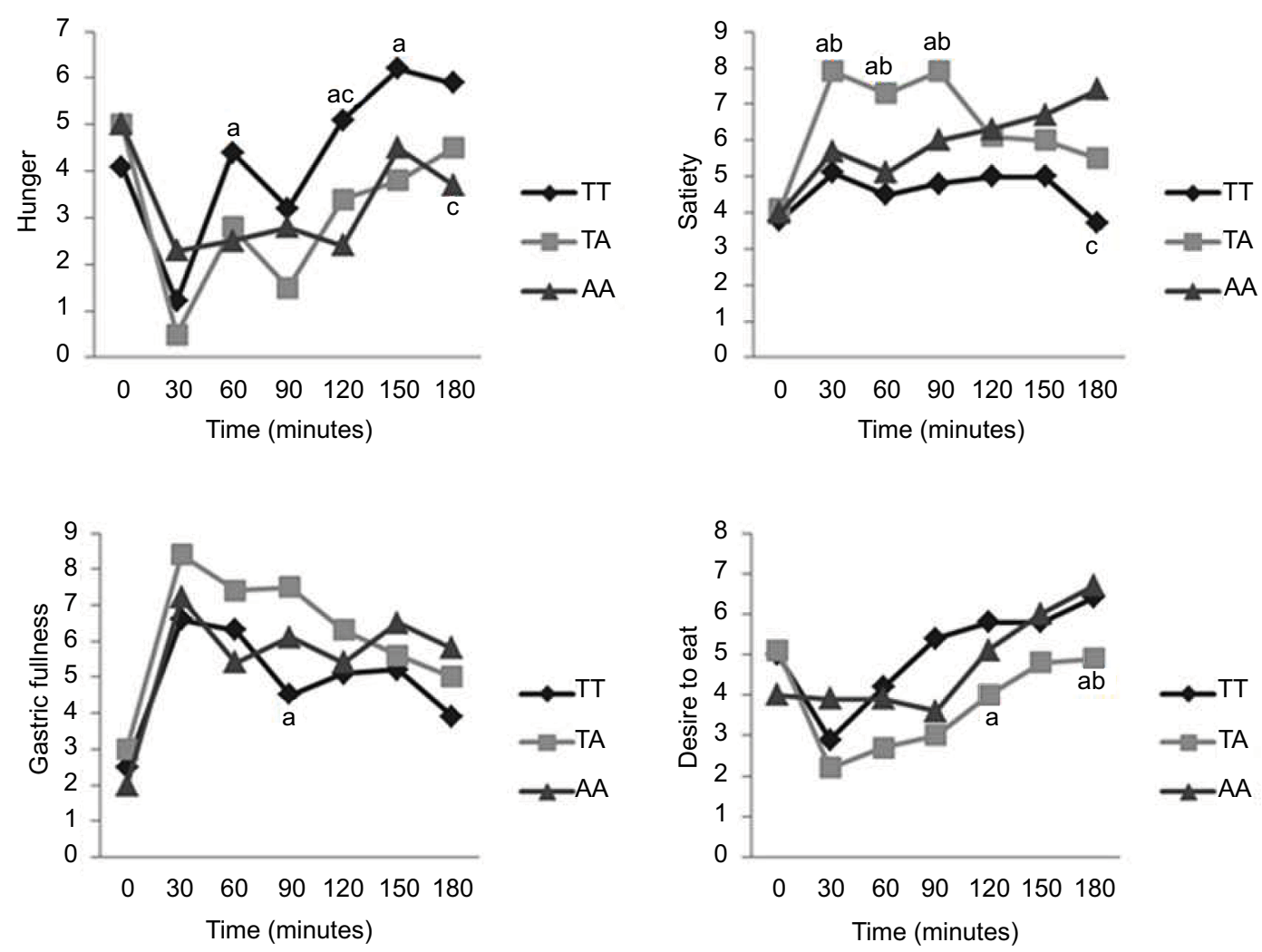

Figure I Behavior of sensations of appetite and satiety by genotype in the pre- and postprandial periods.

Notes: Kruskal-Wallis test used for comparison between genotypes, considering $P$-value $<0.05$. Wilcoxon-Mann-Whitney test used for unpaired data considering $P$-value $<0.05$ when ${ }^{\mathrm{a}} \mathrm{TT}$ versus TA, ${ }^{\mathrm{b}} \mathrm{TA}$ versus AA and ${ }^{\mathrm{C} T T}$ versus AA. The $y$-axes are measured in intensity according to the visual analog scale.

regulation, inflammatory cytokines and food intake in the different genotypes of FTO rs9939609 polymorphism. The main findings of the present study were a reduction of postprandial ghrelin in AA and higher postprandial ghrelin in TT and TA, compared to AA; increased postprandial leptin in AA, a decrease in this hormone in TT and higher postprandial leptin in AA than in TT; higher sensation of hunger in TT and greater sensation of satiety in AA during the postprandial period; desire to eat an appetizer during the postprandial period in individuals with risk allele (A) and lower protein intake per kilogram of weight in the TT genotype and higher consumption of cholesterol and sodium in AA.

The A allele proportion of the FTO rs9939609 reported in this study is in agreement with earlier studies. ${ }^{18,22}$ The research is contradictory in terms of differences in the anthropometric parameters. While several studies have shown an increase in body weight, waist and $\mathrm{HCs}$, and especially in BMI in individuals with the risk allele, ${ }^{10,12,15,19,24}$ other authors do not present differences between the genotypes, ${ }^{22,32}$ similarly to the present study, which can be explained by the population selection, that was homogeneous regarding these parameters.

No differences were found between investigated rs9939609 SNP biochemical parameters (cholesterol total,
LDL, HDL, VLDL, TG, glucose and Homeostatic Model Assessment of Insulin Resistance). However, it was observed that insulin levels were higher in AA than in TT and TA genotypes. Different findings in the literature for insulin have been cited. For example, De Luis et al found an increased release of insulin in the TT genotype ${ }^{33}$ and Shahid et al in the AA genotype, similar to our study. ${ }^{34}$

Most of the women in this study were considered as inactive, which was more prevalent in women who have the risk allele, corroborating with other studies. ${ }^{24,35}$ Although the prevalence of inactive women is high in the AA genotype, studies show that there was no relation between FTO and the level of physical activity in adults, ${ }^{23,36}$ suggesting that the presence of the risk allele is not influencing the level of physical activity in these women. On the other hand, studies have shown that an obesity-increasing effect may be attenuated in $\sim 30 \%$ of individuals who are physically active. ${ }^{32,36}$ For example, it has been shown that people who carry the A allele benefit from practicing physical activity. ${ }^{36}$

Binge eating disorder is associated with current morbid obesity (BMI $\geq 40 \mathrm{~kg} / \mathrm{m}^{2}$ ), and it is observed in over $40 \%$ of such individuals. ${ }^{37}$ Some studies evaluating the relationship between FTO gene polymorphism and the presence of eating 

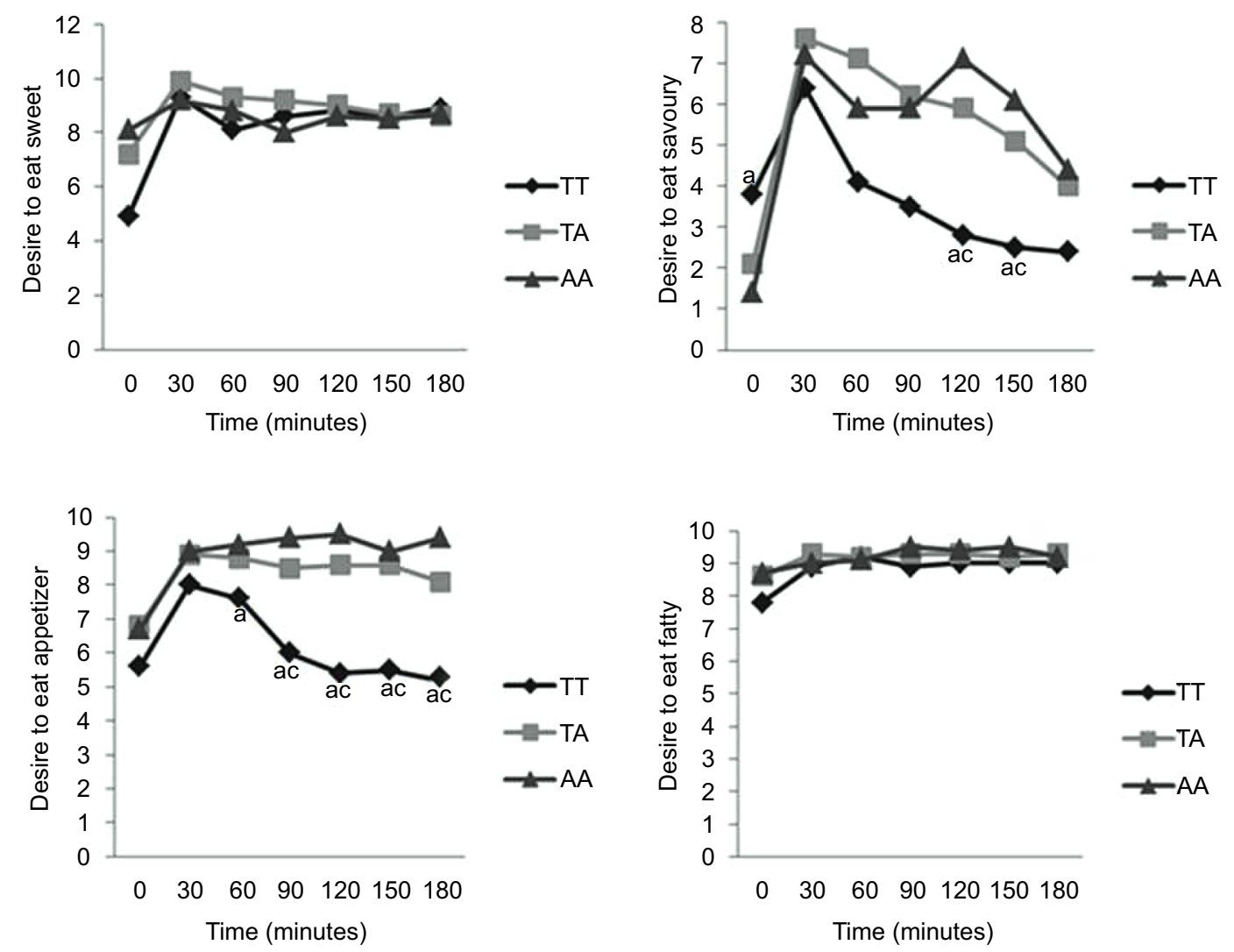

Figure 2 Behavior of food preferences by genotype in the pre- and postprandial periods.

Notes: Kruskal-Wallis test used for comparison between genotypes, considering $P$-value $<0.05$. Wilcoxon-Mann-Whitney test used for unpaired data considering $P$-value $<0.05$ when ${ }^{\mathrm{T}} \mathrm{TT}$ versus TA, ${ }^{\mathrm{b}} \mathrm{TA}$ versus AA and ${ }^{\mathrm{C}} \mathrm{TT}$ versus AA. The $y$-axes are measured in intensity according to the visual analog scale.

disorders show the role of the rs9939609 SNP in satiety responsiveness, ${ }^{38}$ which could be explained by high FTO expression in the hypothalamic regions of the brain associated with appetite regulation..$^{39}$ In addition, a more recent study of 250 lean subjects with eating disorders found that the presence of the risk allele was associated with binge eating behavior. ${ }^{40}$ Interestingly, it was observed in the present study that patients with the AA genotype presented moderate binge eating according to the binge eating score.

In the literature, it has been established that ghrelin affects appetite and food intake. However, researches have shown that polymorphism may influence the release of this hormone in patients with obesity. The association between rs9939609 and ghrelin secretion is still unknown. Arrizabalaga et al observed that ghrelin at the baseline showed no difference between rs9939609 genotypes, similar to our findings. ${ }^{41}$ Nevertheless, there was a decrease in ghrelin in the postprandial period, when compared to the release of this hormone pre- and postprandially in our morbidly obese population. The opposite ghrelin pattern was observed in a similar study. ${ }^{42}$
This study evaluated pre- and postprandial leptin, showing a decrease of this hormone in the TT genotype 3 hours after an isocaloric meal. Some studies evaluating leptin in the baseline show that there is no difference between genotypes presenting the risk allele, ${ }^{33,43,44}$ corroborating with our findings. Otherwise, other studies observed a positive association of rs9939609 with leptin. ${ }^{34,41,45,46}$

No differences were found in the literature on inflammatory cytokines between genotypes with or without the risk allele in the baseline. ${ }^{33,43,45,46}$ Our findings showed increased IL6 in TT and TA, and TT presented higher IL6 than AA. Among all adipokines related to inflammatory processes, IL6, TNF $\alpha$, leptin and adiponectin have received special attention in the literature. Leptin synthesis is stimulated by TNF $\alpha$ and IL6, contributing to satiety and maintaining the inflammatory state. ${ }^{16}$

Studies have shown that carriers of the rs9939609 A genotype have altered postprandial satiety levels as recorded by VAS completed periodically. ${ }^{42,47,48}$ While some studies have shown lower postprandial fullness ${ }^{47}$ and higher postprandial appetite levels in AA homozygotes compared to 
Table 3 Food intake data of the population expressed in median and quartile

\begin{tabular}{|c|c|c|c|c|c|}
\hline Variables & Total (70) & TT (23) & AT (35) & AA (12) & $P$-value \\
\hline Calories & $2,229(1,758 ; 2,672)$ & $2,158(1,796 ; 2,404)$ & $2,362(1,644 ; 2,672)$ & $2,700(2,029 ; 3,762)$ & 0.204 \\
\hline Carbohydrates (\%) & $51(47 ; 54)$ & $50(47 ; 53)$ & $52(47 ; 56)$ & $50(44 ; 54)$ & 0.487 \\
\hline Proteins (\%) & $17(11 ; 29)$ & $17(14 ; 18)$ & $18(15 ; 19)$ & $18(15 ; 20)$ & 0.086 \\
\hline $\mathrm{PTNg} / \mathrm{kg}$ BW & $0.73(0.56 ; 0.88)$ & $0.69(0.55 ; 0.78)^{\mathrm{a}, \mathrm{c}}$ & $0.79(0.56 ; 0.88)$ & $0.74(0.7 ;$ I.4) & 0.048 \\
\hline Total fats (\%) & $32(25 ; 35)$ & $33(28 ; 36)$ & $30(24 ; 35)$ & $33(27 ; 36)$ & 0.487 \\
\hline SFA (\%) & $23(20 ; 28)$ & $23(20 ; 28)$ & $23(20 ; 27)$ & $22(16 ; 28)$ & 0.351 \\
\hline MFA (\%) & $24(17 ; 27)$ & $24(20 ; 25)$ & $23(17 ; 28)$ & $26(12 ; 29)$ & 0.644 \\
\hline PFA (\%) & $17(12 ; 21)$ & $16(12 ; 20)$ & $17(12 ; 21)$ & $16(11 ; 21)$ & 0.728 \\
\hline Cholesterol (mg) & $268.6(186.7 ; 401.6)$ & $226.8(193.4 ; 288.8)$ & $288.2(168.4 ; 390.2)$ & $454.5(286.3 ; 529.4)^{\mathrm{a}, \mathrm{b}}$ & 0.012 \\
\hline Fibers $(g)$ & $12.4(10.1 ; 17.1)$ & $12.2(10.2 ; 17.5)$ & $13(10 ; 16)$ & $12.4(7.8 ; 18.9)$ & 0.747 \\
\hline Vitamin A $(\mu g)$ & $725.1(362.9 ;$ I I76.I) & $660.3(331.4 ; 1024.8)$ & $829.6(528.5 ; 1235.4)$ & $589.8(385.0 ; 4642.6)$ & 0.563 \\
\hline Vitamin D $(\mu g)$ & $1.9(1.3 ; 3.3)$ & $1.8(1.3 ; 2.9)$ & $1.8(1.2 ; 4.0)$ & $2.0(1.4 ; 4.1)$ & 0.442 \\
\hline Vitamin E (mg) & I $4.4(8.1 ; 24.7)$ & I $5.8(8.9 ; 23.7)$ & $12.2(7.2 ; 24.6)$ & I5.I (7.7; 32.5) & 0.487 \\
\hline Vitamin C (mg) & $91.0(30.6 ; 129.3)$ & 66.6 (29.8; 98.7) & $79.9(27.6 ; 100.2)$ & $118.5(39.4 ; 161.13)$ & 0.343 \\
\hline Vitamin BI (mg) & $1.2(0.9 ; 1.7)$ & $1.2(0.7 ; 1.6)$ & $1.2(0.9 ; 1.8)$ & $\mathrm{I} .4(\mathrm{I} . \mathrm{I} ; 2.3)$ & 0.249 \\
\hline Vitamin B2 (mg) & $1.3(0.9 ; 1.8)$ & $1.2(0.8 ; 1.4)$ & $1.2(0.8 ; 1.9)$ & $1.6(1.1 ; 3.3)$ & 0.081 \\
\hline Vitamin B3 (mg) & $21.5(17.8 ; 25.8)$ & $19.3(16.6 ; 22.5)^{\mathrm{a}, \mathrm{c}}$ & $23.2(18.5 ; 26.5)$ & $24.0(19.2 ; 29.4)$ & 0.016 \\
\hline Vitamin B5 (mg) & $2.7(2.1 ; 3.6)$ & $2.3(1.9 ; 2.7)$ & $2.8(2.0 ; 3.5)$ & $4.1(2.7 ; 6.1)^{b, c}$ & 0.001 \\
\hline Vitamin B6 (mg) & I.3 (0.9; I.7) & I.I $(0.8 ; 1.5)$ & $1.3(1.1 ; 1.8)$ & $1.6(1.1 ; 5.9)^{c}$ & 0.009 \\
\hline Vitamin B9 $(\mu \mathrm{g})$ & II3.I (78.0; I57.7) & $108.7(75.3 ;$ I 40.1$)$ & II 5.9 (75.7; I66.8) & II 7.2 (9I.0; 258.6) & 0.151 \\
\hline Vitamin BI2 $(\mu \mathrm{g})$ & $3.2(1.7 ; 6.0)$ & $2.5(1.6 ; 3.2)$ & $3.4(1.6 ; 6.5)$ & $4.6(2.4 ; 8.1)^{c}$ & 0.021 \\
\hline Calcium (mg) & $561.8(332.8 ; 696.0)$ & $535.1(300.7 ; 647.1)$ & $634.4(378.2 ; 912.1)$ & $593.9(351.1 ; 673.9)$ & 0.089 \\
\hline Phosphor (mg) & $1057.1(758.4 ; 1253.1)$ & $943.4(738.7 ; 1132.5)$ & $1063.1(761.8 ; 1401.3)$ & I I 44.8 (912.2; 1322.2) & 0.068 \\
\hline Magnesium (mg) & 167.5 (I23.1; 209.7) & $138.8(120.2 ; 175.5)$ & I75.5 (II9.4; 225.6) & I86.2 (I25.I; 282.5) & 0.060 \\
\hline Iron (mg) & $12.4(9.2 ; 17.8)$ & $10.3(8.7 ; 17.0)$ & $14.6(9.2 ; 17.8)$ & $15.3(10.1 ; 19.8)$ & 0.076 \\
\hline Zinc (mg) & $7.4(5.4 ; 11.6)$ & $6.6(4.9 ; 9.3)$ & $8.7(5.6 ;$ I I.8) & $8.6(6.0 ; 11.8)$ & 0.098 \\
\hline Copper (mg) & $0.8(0.6 ; 1.2)$ & $0.7(0.6 ; 1.0)$ & $1.0(0.6 ; 1.2)$ & $1.2(0.5 ; 2.7)$ & 0.193 \\
\hline lodine (mg) & $15.4(3.7 ; 35.1)$ & II. $4(2.4 ; 20.0)$ & $16.0(6.1 ; 39.6)$ & $19.6(4.8 ; 37.5)$ & 0.259 \\
\hline Selenium (mg) & 64.7 (44.4; 95.2) & $52.7(41.6 ; 69.3)$ & $67.6(44.6 ; 95.0)$ & $91.1(60.6 ; 115.1)^{b, c}$ & 0.017 \\
\hline Manganese (mg) & I.2 (0.8; I.7) & I.I $(0.8 ; 1.3)$ & $1.3(1.0 ; 1.8)$ & $\mathrm{I} .4(0.5 ; \mathrm{I} .8)$ & 0.179 \\
\hline Potassium (mg) & $166 \mid .7(1 \mid 44.6 ; 2198.4)$ & I $382.5(|077.0 ;| 758.2)^{\mathrm{a}, \mathrm{c}}$ & $1803.9(1211.9 ; 2317.4)$ & $1995.4(1|47.4 ; 3| 14.8)$ & 0.041 \\
\hline Sodium (mg) & $2450.0(1648.2 ; 2859.8)$ & $2345.6(1653.1 ; 2606.2)$ & $2240.1(1620.7 ; 2604.4)$ & $2756.2(|868.9 ; 4| 9 \mid . I)^{b, c}$ & 0.049 \\
\hline
\end{tabular}

Notes: Data of the population were expressed in median and quartile. Kruskal-Wallis test used for comparison between genotypes, considering $P$-value $<0.05$. WilcoxonMann-Whitney test for unpaired data considering $P$-value $<0.05$ when ${ }^{a}$ TT versus TA, ${ }^{\mathrm{b} T A}$ versus AA and ${ }^{\mathrm{T}}$ TT versus AA.

Abbreviations: MFA, monounsaturated fatty acid; PFA, polyunsaturated fatty acid; PTNg/kg BW, grams of protein per kilogram of body weight; SFA, saturated fatty acid.

TT homozygotes for rs $9939609,{ }^{42}$ our results showed the opposite. The TT genotype women had elevated hunger and decreased satiety, agreeing with the study carried out by Den Hoed et al ${ }^{48}$ Surprisingly, fullness was lower in the TT genotype, and desire to eat an appetizer was higher in women with the risk allele throughout the postprandial period.

This is the first time an analysis of the food intake, among morbidly obese individuals, is performed in detail, showing the values of carbohydrates, fibers, proteins, saturated and unsaturated fats, dietary cholesterol, vitamins and minerals. Participants with the TT genotype showed lower consumption of protein per kilogram of body weight and increased consumption of cholesterol and sodium, suggesting higher intake of food from animal products, despite there being no differences in protein (\%) and total fat intake (\%).

Although the presence of polymorphism in rs9969309 seems to contribute to the alteration of appetite and food intake, several articles in the literature are controversial regarding the energy and macronutrients intake, and these divergences may be explained by inaccuracies of measuring dietary intake in the obese. While most of the research does not show differences in energy and macronutrient intake between genotypes, ${ }^{23,24,33,47,49,50}$ some authors note a highenergy intake in individuals carrying the risk allele. ${ }^{22,32,51}$ However, it remains to be confirmed which components of food intake are predominantly FTO targets.

In this study, we used a well-characterized cohort of participants. Furthermore, we analyzed the role of the genetic variant on hormone release and the feelings of hunger and satiety, as well as eating habits and physical activity in a population of Brazilian women with morbid obesity, who tend to be more difficult to recruit. However, limitations should also be observed: 1) this study was carried out in a group with a low level of schooling, which may influence the lack 
of understanding of certain answers; 2) many participants live in poorer communities and, therefore, may have increased difficulty accessing certain services (e.g., supermarkets, gyms and hospitals); and 3) only one FTO SNP was evaluated in this study, and it is not possible to clarify whether this gene has a direct relationship with feeding behavior.

\section{Conclusion}

The presence of the risk allele (A) occurred in almost half of the women with morbid obesity, and this risk allele increases the prevalence of low physical activity. AA homozygotes did not completely affect dietary intake, but dietary sodium and cholesterol intake was high in this group, deserving further investigation in relation to nutritional quality of the diet.

The levels of ghrelin decreased postprandially in women with AA genotypes, and these findings corroborated with the sensations of lower hunger observed in this group, as occurred in the TT genotype, where leptin levels increased in the postprandial period and the feeling of satiety was lower.

An interesting finding was in relation to the desire to eat an appetizer throughout the postprandial period - every 30 minutes - in women with the AA genotype and the presence of moderate binging. It is suggested that these women had the urge to eat all the time, even with the release of hormones involved in hunger and satiety. Additionally, the presence of the risk allele may interfere both in physiologic responses and in eating behavior in cases of morbid obesity.

These findings suggest that genetics may exert an influence on physiologic factors and might alter eating behavior. However, further clarification involving other genes, environmental factors and lifestyle is needed to better understand all the organic complexity involved in extreme obesity.

\section{Acknowledgments}

We thank the students of scientific initiation and, in particular, the volunteers. This work was supported by grants from the Coordenação de Aperfeiçoamento de Pessoal de Nível Superior (CAPES).

\section{Disclosure}

The authors report no conflicts of interest in this work.

\section{References}

1. GBD 2015 Obesity Collaborators, Afshin A, Forouzanfar MH, Reitsma $\mathrm{MB}$, et al. Health effects of overweight and obesity in 195 Countries over 25 years. $N$ Engl J Med. 2017;377(1):13-27.

2. WHO. World Health Organization. Obesity and overweight. 2016; Available from: http://www.who.int/mediacentre/factsheets/fs311/en/. Accessed June 26, 2017.

3. Withrow D, Alter DA. The economic burden of obesity worldwide: a systematic review of the direct costs of obesity. Obes Rev. 2011;12(2):131-141.
4. IMHA. Institute for Metrics and Health Assessment. Available from: http://www.Overweight and Obesity Viz/. 2015. Accessed June 17, 2017.

5. Ng M, Fleming T, Robinson M, et al. Global, regional, and national prevalence of overweight and obesity in children and adults during 1980-2013: a systematic analysis for the Global Burden of Disease Study 2013. Lancet. 2014;384(9945):766-781.

6. Cesare MD, Bentham Jm, Stevens GA, et al. Trends in adult body-mass index in 200 countries from 1975 to 2014: a pooled analysis of 1698 population-based measurement studies with 19.2 million participants. Lancet. 2016;387(10026):1377-1396.

7. BRASIL. VIGITEL - Fatores de risco e proteção para doenças crônicas não transmissíveis obtidos por inquérito telefônico. 2016. Available from: http://portalarquivos.saude.gov.br/images/pdf/2017/junho/07/ vigitel_2016_jun17.pdf. Accessed June 16, 2017.

8. de Oliveira ML, Santos LM, da Silva EN. Direct healthcare cost of obesity in Brazil: an application of the cost-of-illness method from the perspective of the public health system in 2011. PLoS One. 2015;10(4): e0121160.

9. Swinburn BA, Sacks G, Hall KD, et al. The global obesity pandemic: shaped by global drivers and local environments. Lancet. 2011; 378(9793):804-814.

10. Xia Q, Grant SFA. The genetics of human obesity. Ann NY Acad Sci. 2013;1281(1):178-190.

11. Fall T, Ingelsson E. Genome-wide association studies of obesity and metabolic syndrome. Mol Cell Endocrinol. 2014;382(1):740-757.

12. Speliotes EK, Willer CJ, Berndt SI, et al. Association analyses of 249,796 individuals reveal eighteen new loci associated with body mass index. Nat Genet. 2010;42(11):937-948.

13. Jia G, Fu Y, Zhao X, et al. N6-methyladenosine in nuclear RNA is a major substrate of the obesity-associated FTO. Nat Chem Biol. 2011;7(12):885-887.

14. Gerken T, Girard CA, Tung Y-CL, et al. The obesity-associated FTO gene encodes a 2-oxoglutarate-dependent nucleic acid demethylase. Science. 2007;318(5855):1469-1472.

15. Ben-Haim MS, Moshitch-Moshkovitz S, Rechavi G. FTO: linking m6A demethylation to adipogenesis. Cell Res. 2015;25(1):3-4.

16. Fruhbeck G, Gomez-Ambrosi J, Muruzabal FJ, Burrell MA. The adipocyte: a model for integration of endocrine and metabolic signaling in energy metabolism regulation. Am J Physiol Endocrinol Metab. 2001;280(6):827-847.

17. Fredriksson R, Hagglund M, Olszewski PK, et al. The obesity gene, FTO, is of ancient origin, up-regulated during food deprivation and expressed in neurons of feeding-related nuclei of the brain. Endocrinology. 2008;149(5):2062-2071.

18. Frayling TM. Genome-wide association studies provide new insights into type 2 diabetes aetiology. Nat Rev Genet. 2007;8(9):657-662.

19. Scuteri A, Sanna S, Chen WM, et al. Genome-wide association scan shows genetic variants in the FTO gene are associated with obesityrelated traits. PLoS Genet. 2007;10(1):43-47.

20. Illangasekera YA, Kumarasiri RP, Fernando DJ, Dalton CF. Association of FTO and near MC4R variants with obesity measures in urban and rural dwelling Sri Lankans. Obes Res Clin Pract. 2016;10(Supp1 1):S117-S124.

21. Gulati P, Yeo GS. The biology of FTO: from nucleic acid demethylase to amino acid sensor. Diabetologia. 2013;56(10):2113-2121.

22. Speakman JR, Rance KA, Johnstone AM. Polymorphisms of the FTO gene are associated with variation in energy intake, but not energy expenditure. Obesity (Silver Spring). 2008;16(8):1961-1965.

23. Speakman JR. The "Fat Mass and Obesity Related" (FTO) gene: mechanisms of impact on obesity and energy balance. Curr Obes Rep. 2015;4(1):73-91.

24. Oyeyemi BF, Ologunde CA, Olaoye AB, Alamukii NA. FTO gene associates and interacts with obesity risk, physical activity, energy intake, and time spent sitting: pilot study in a Nigerian population. $J$ Obes. 2017;2017:3245270.

25. WHO. World Health Organization. Waist Circumference and WaistHip Ratio. 2011; Available from: http://apps.who.int/iris/bitstr eam/10665/44583/1/9789241501491_eng.pdf. Accessed August 7, 2017. 
26. Sampaio LR, Silva MdCMd, Roriz AKC, Leite VR. Inquérito Alimentar [Food Inquiry]. In: Sampaio, L.R. Avaliação Nutricional. Vol 1. EDUFBA 2012. Portuguese.

27. Matsudo S, Araujo T, Matsudo V, et al. Questionário Internacional de Atividade Física (IPAQ): Estudo de validade e reprodutibilidade no Brasil [International Physical Activity Questionnaire (IPAQ): Study of validity and reproducibility in Brazil]. Revista Brasileira de Atividade Física e Saúde. 2001;6(2):5-18. Portuguese.

28. Freitas S, Lopes CS, Coutinho W, Appolinario JC. [Tradução e adaptação para o português da Escala de Compulsão Alimentar Periódica]. Revista Brasileira de Psiquiatria. 2001;23(4):215-220. Portuguese.

29. Flint A, Raben A, Blundell JE, Astrup A. Reproducibility, power and validity of visual analogue scales in assessment of appetite sensations in single test meal studies. Int J Obes Relat Metab Disord. 2000;24(1):38-48.

30. Hardy GH. Mendelian proportions in a mixed population. Science. 1908;28(706):49-50.

31. Weinberg W. Über den Nachweis der Vererbung beim Menschen. Vol 64. Jahresh Wuertt Ver vaterl Natkd; 1908.

32. Loos RJ, Yeo GS. The bigger picture of FTO - the first GWAS-identified obesity gene. Nat Rev Endocrinol. 2014;10(1):51-61.

33. De Luis DA, Aller R, Izaola O, Primo D, Romero E. Association of the rs9939609 gene variant in FTO with insulin resistance, cardiovascular risk factor and serum adipokine levels in obese patients. Nutr Hosp. 2016;33(5):573.

34. Shahid A, Rana S, Saeed S, Imran M, Afzal N, Mahmood S. Common variant of FTO gene, rs9939609, and obesity in Pakistani females. Biomed Res Int. 2013;2013:324093.

35. Muc M, Padez C, Manco L. Influence of physical activity on the association between the FTO variant rs 9939609 and adiposity in young adults Am J Human Biol. 2015;27(5):734-738.

36. Kilpelainen TO, Qi L, Brage S, et al. Physical activity attenuates the influence of FTO variants on obesity risk: a meta-analysis of 218,166 adults and 19,268 children. PLoS Med. 2011;8(11):e1001116.

37. Hudson JI, Hiripi E, Pope HG Jr, Kessler RC. The prevalence and correlates of eating disorders in the National Comorbidity Survey Replication. Biol Psychiatry. 2007;61(3):348-358.

38. Wardle J, Carnell S, Haworth CMA, Farooqi IS, O'Rahilly S, Plomin R. Obesity associated genetic variation in FTO is associated with diminished satiety. J Clin Endocrinol Metab. 2008;93(9):3640-3643.

39. Jonassaint CR, Szatkiewicz JP, Bulik CM, et al. Specific common variants of the obesity-associated FTO gene are not associated with psychological and behavioral eating disorder phenotypes. Am J Med Genet. 2011;156(4):454-461.
40. Castellini G, Franzago M, Bagnoli S, et al. Fat mass and obesityassociated gene (FTO) is associated to eating disorders susceptibility and moderates the expression of psychopathological traits. PLoS One. 2017;12(3):e0173560.

41. Arrizabalaga M, Larrarte E, Margareto J, Maldonado-Martin S, Barrenechea L, Labayen I. Preliminary findings on the influence of FTO rs9939609 and MC4R rs17782313 polymorphisms on resting energy expenditure, leptin and thyrotropin levels in obese non-morbid premenopausal women. J Physiol Biochem. 2014;70(1):255-262.

42. Karra E, O’Daly OG, Choudhury AI, et al. A link between FTO, ghrelin, and impaired brain food-cue responsivity. J Clin Invest. 2013;123(8):3539-3551.

43. Olza J, Ruperez AI, Gil-Campos M, et al. Influence of FTO variants on obesity, inflammation and cardiovascular disease risk biomarkers in Spanish children: a case-control multicentre study. BMC Med Genet. 2013;14:123.

44. Labayen I, Margareto J, Maldonado-Martin S, et al. Independent and combined influence of the FTO rs9939609 and MC4Rrs17782313 polymorphisms on hypocaloric diet induced changes in body mass and composition and energy metabolism in non-morbid obese premenopausal women. Nutr Hosp. 2015;31(5):2025-2032.

45. Zimmermann E, Skogstrand K, Hougaard DM, et al. Influences of the common FTO rs9939609 variant on inflammatory markers throughout a broad range of body mass index. PLoS One. 2011;6(1):e15958.

46. de Luis DA, Aller R, Conde R, et al. [Relation of the rs9939609 gene variant in FTO with cardiovascular risk factor and serum adipokine levels in morbid obese patients]. Nutr Hosp. 2012;27(4):1184-1189. Spanish.

47. Douglas A, Yaqoob P, Givens DI, Reynolds CK, Minihane AM. The impact of obesity-related SNP on appetite and energy intake. Br J Nutr. 2013;110(6):1151-1156.

48. den Hoed M, Westerterp-Plantenga MS, Bouwman FG, Mariman EC, Westerterp KR. Postprandial responses in hunger and satiety are associated with the rs9939609 single nucleotide polymorphism in FTO. Am J Clin Nutr. 2009;90(5):1426-1432.

49. Gustavsson J, Mehlig K, Leander K, et al. FTO gene variation, macronutrient intake and coronary heart disease risk: a gene-diet interaction analysis. Eur J Nutr. 2016;55(1):247-255.

50. Qi Q, Kilpeläinen TO, Downer MK, et al. FTO genetic variants, dietary intake and body mass index: insights from 177330 individuals. Hum Mol Genet. 2014;23(25):6961-6972.

51. Church C, Moir L, McMurray F, et al. Overexpression of Fto leads to increased food intake and results in obesity. Nat Genet. 2010;42(12): 1086-1092.

Diabetes, Metabolic Syndrome and Obesity: Targets and Therapy

Dovepress

\section{Publish your work in this journal}

Diabetes, Metabolic Syndrome and Obesity: Targets and Therapy is an international, peer-reviewed open-access journal committed to the rapid publication of the latest laboratory and clinical findings in the fields of diabetes, metabolic syndrome and obesity research Original research, review, case reports, hypothesis formation, expert opinion and commentaries are all considered for publication. The manuscript management system is completely online and includes a very quick and fair peer-review system, which is all easy to use. Visit http://www.dovepress.com/testimonials.php to read real quotes from published authors. 